\title{
Environmental impact of materials used in technical equipments: an overview on different methods
}

\author{
L. Marletta, G. Evola \& F. Sicurella \\ Department of Industrial Engineering, University of Catania, Italy
}

\begin{abstract}
In this paper the environmental impact of the most important materials used for the production of technical equipments in buildings is assessed. The analysis is performed according to Life Cycle Assessment (LCA) methodology. The LCA of a product is conducted by compiling an inventory of relevant inputs and outputs, and by evaluating the potential environmental impact associated with them. In the evaluation phase different impact categories are defined; normalisation and weighting are also performed to obtain a single score. All these phases, except inventory, can be carried out in different ways, according to different impact assessment methodologies (LCIA). For this reason, it is useful to compare the results provided by some of the most used methods, namely Eco-indicator 99 and EPS 2000, in order to understand how the assessment can be influenced by the choice of the methodology. In addition, three different cultural perspectives (Egalitarian, Hierarchist, Individualist) are considered when using the Eco-indicator 99 method, since this choice influences calculation and weighting processes. In conclusion, this study will provide an environmental ranking of the most important materials used in technical equipments of buildings, according to different methods and calculation hypotheses. The results will be useful for future analyses concerning the impact of technological systems in buildings.
\end{abstract}

Keywords: life cycle assessment, embodied energy, materials, methods.

\section{Introduction}

Achieving sustainable development is fundamental if environment has to be preserved for future generations. To this aim, tools have been developed to 
measure the potential environmental impact of products or services. One of the most popular tools is Life Cycle Assessment (LCA), a multi-disciplinary and systematic procedure which, according to SETAC, represents "a process to evaluate the environmental burdens associated with a product, process or activity, by identifying and quantifying energy and materials used and wastes released to the environment [...]. The assessment includes the entire life cycle of a product, from the extraction of the raw materials to the final disposal" [1].

Another parameter useful in environmental analysis is the Embodied Energy, defined as the overall energy demand, valued as primary energy, which arises from the production, use and disposal of a product or service. Table 1 shows the Embodied Energy (EE) associated with the main materials used in technical equipments in buildings.

Table 1: Embodied Energy (EE, MJ/kg) in technical equipments of buildings.

\begin{tabular}{|c|c|c|c|}
\hline & MATERIAL & EE & Ref \\
\hline \multirow{4}{*}{ Ferrous } & Steel & 26,7 & {$[2]$} \\
\cline { 2 - 4 } & Stainless St. & 79,9 & {$[2]$} \\
\cline { 2 - 4 } & Cast Iron & 60 & {$[2]$} \\
\hline \multirow{2}{*}{$\begin{array}{c}\text { Non } \\
\text { ferrous }\end{array}$} & Copper & 72,9 & {$[2]$} \\
\cline { 2 - 4 } & Aluminium & 164 & {$[2]$} \\
\hline
\end{tabular}

\begin{tabular}{|c|c|c|c|}
\hline & MATERIAL & EE & Ref \\
\hline \multirow{2}{*}{ Plastics } & PVC & 77,2 & {$[2]$} \\
\cline { 2 - 4 } & HDPE & 64,9 & {$[2]$} \\
\hline \multirow{3}{*}{ Insulat. } & Glass wool & 31,3 & {$[3]$} \\
\cline { 2 - 4 } & Rock wool & 15,7 & {$[2]$} \\
\cline { 2 - 4 } & Polyureth. & 99,8 & $*$ \\
\hline
\end{tabular}

*: average data for European factories.

\section{How to perform the Life Cycle Assessment}

According to the ISO 14040 series [4], an LCA consists of four steps:

1. Goal and scope definition [5]: the goal and the object of the analysis are defined in terms of functional unit, as well as the system boundaries.

2. Inventory analysis [5]: data are collected concerning the relevant inputs (raw materials and energy consumption) and outputs (emissions and wastes) related to production, use and disposal of the functional unit.

3. Impact assessment [6]: the environmental impact due to inputs and outputs from the inventory analysis is evaluated.

4. Interpretation [7]: the results of the impact assessment are analysed, and possible improvements are identified

When performing the impact assessment, different methods are available, all of which are based on the definition of a number of impact categories, such as climate change, land use, resources consumption and effects on human health. The quantification of the effects on each impact category is performed by means of impact indicators, whose evaluation needs two different steps [8]:

1. Classification: every emission or resource resulting from the inventory analysis is associated with one or more impact categories. 
2. Characterization: mathematical and/or empirical models, taken from physics, natural science or economics, are used to evaluate the contribution of every emission to the impact categories. As an example, if the Global Warming Potential (GWP) is chosen as the indicator for the category "Climate Change", the value of GWP for every gas released to the atmosphere will be determined.

Apart from classification and characterization, other optional steps can be performed, such as normalization, grouping and weighting. Normalization is carried out by dividing every impact indicator by a reference value; this operation makes impact indicators dimensionless, thus allowing comparisons between different impact categories. Grouping involves sorting and ranking results across the impact categories, and may result in a limited number of damage categories. On the other hand, weighting means combining different impact or damage categories into a single score or index; numerical factors are used as weights, according to the importance attributed to every different impact. Due to the subjectivity of the weighting factors, ISO 14042 recommends not to use weighted results for public.

Table 2: $\quad$ Categories and indicators defined in the Eco-indicator 99 method.

\begin{tabular}{|c|c|c|c|}
\hline Damage Category & Impact Category & Abbr. & Impact Indicator \\
\hline \multirow{4}{*}{ Human Health } & Carcinogenesis & Ca. & DALY \\
\cline { 2 - 4 } & Respiratory effects & R.I. & DALY \\
\cline { 2 - 4 } & Ioniz. Radiation & I.R. & DALY \\
\cline { 2 - 4 } & Ozone layer depletion & Oz. & DALY \\
\cline { 2 - 4 } & Climate change & C.C. & $\mathrm{DALY}$ \\
\hline \multirow{3}{*}{ Ecosystem Quality } & Ecotoxicity & Ec. & $\mathrm{PDF} \cdot \mathrm{m}^{2} \cdot \mathrm{yr}$ \\
\cline { 2 - 4 } & Acidificat. / Eutrophicat. & A.E. & $\mathrm{PAF} \cdot \mathrm{m}^{2} \cdot \mathrm{yr}$ \\
\cline { 2 - 4 } & Land use & L.U. & $\mathrm{PDF} \cdot \mathrm{m}^{2} \cdot \mathrm{yr}$ \\
\hline \multirow{2}{*}{ Resources } & Minerals & Mi. & $\mathrm{MJ}$ surplus \\
\cline { 2 - 4 } & Fossil fuels & F.F. & MJ surplus \\
\hline
\end{tabular}

\section{The Eco-indicator 99 method}

In the Eco-indicator 99 method, ten impact categories are defined, belonging to three damage categories, as shown in Table 2. Impact indicators are defined as follows:

- Human health: The impact is measured in DALYs (Disability adjusted life years), to quantify disabilities and diseases caused by emissions to natural environment.

- Ecosystem quality: The impact is measured through the Potentially Disappeared Fraction (PDF) of plants and species; for Acidification and Eutrophication the Potentially Affected Fraction (PAF) is used. 
- Resources: the impact on resource depletion is evaluated through MJ surplus, which is the amount of additional energy future generations will spend to extract resources, due to their lower concentration.

Normalisation is based on the present overall impact measured within Europe. As far as weighting is concerned, three cultural perspectives are considered, which reflect different and well-defined attitudes towards environmental issues. Table 3 reports the weighting factors for each cultural perspective, together with a fourth "average" weighting set determined through a panel procedure. In the following the average weighting set will be adopted.

Table 3: $\quad$ Weighting factors associated with different weighting sets.

\begin{tabular}{|c|c|c|c|c|}
\hline & Egalitarian & Hierarchist & Individualist & Average \\
\hline Human Health & 0,5 & 0,4 & 0,25 & 0,4 \\
\hline Ecosystem quality & 0,3 & 0,3 & 0,55 & 0,4 \\
\hline Resources & 0,2 & 0,3 & 0,2 & 0,2 \\
\hline
\end{tabular}

It must be underlined that the adoption of the cultural perspective influences characterization as well as weighting. This means that, even if we use the same average set for weighting, three different results may be obtained. Further information concerning cultural perspectives can be found in [9].

Figure 1 shows the final score for materials used in technical equipments according to Hierarchist and Individualist perspective. The functional unit (FU) corresponds to one kilogram of material; no disposal scenario has been considered (cradle-to-gate analysis). Egalitarian perspective has not been represented, as the difference with Hierarchist perspective is not relevant. Moreover, the contribution of every damage category to the final score is highlighted; the percentage distribution into impact categories is shown in Figure 2 for the most outstanding cases (contributions lower than $0.5 \%$ are not shown).
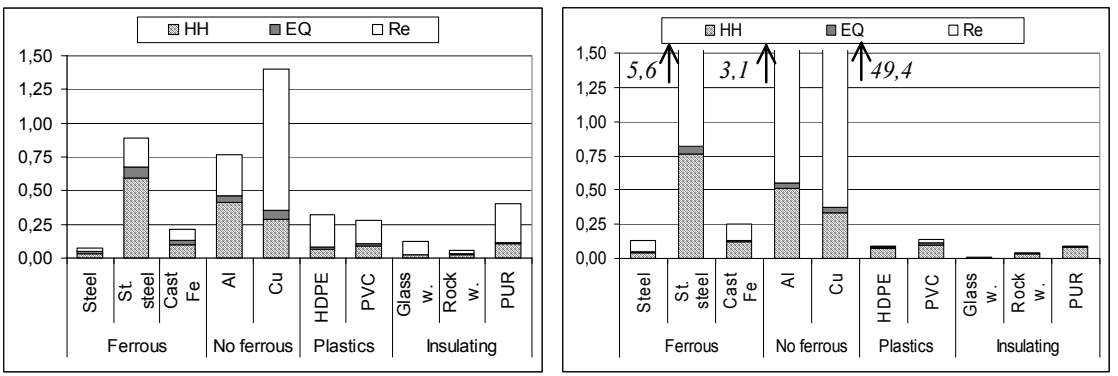

Figure 1: Eco-indicator 99 scores $(\mathrm{Pt} / \mathrm{kg})$ for Hierarch. (left) and Individ. (right).

Under the Hierarchist perspective, copper is the most impactive material $(1.4 \mathrm{Pt} / \mathrm{kg}$, see Figure 1). Most of its environmental impact is related to the 
category "Resources". A clarification of this point may be provided by Figure 2; here it is shown that the main contribution $(62.4 \%)$ comes from the impact category "Minerals". Studies concerning the concentration of minerals in the earth crust have shown that copper concentration will lower at a rate faster than other materials, yielding concern about its extraction. Aluminium, which shows an Embodied Energy almost twice as bigger as copper (see Table 1), presents a lower score $(0.76 \mathrm{Pt} / \mathrm{kg})$; once again, the difference is mainly attributable to "Minerals", due to the lower scarcity of bauxite in a world-wide perspective.
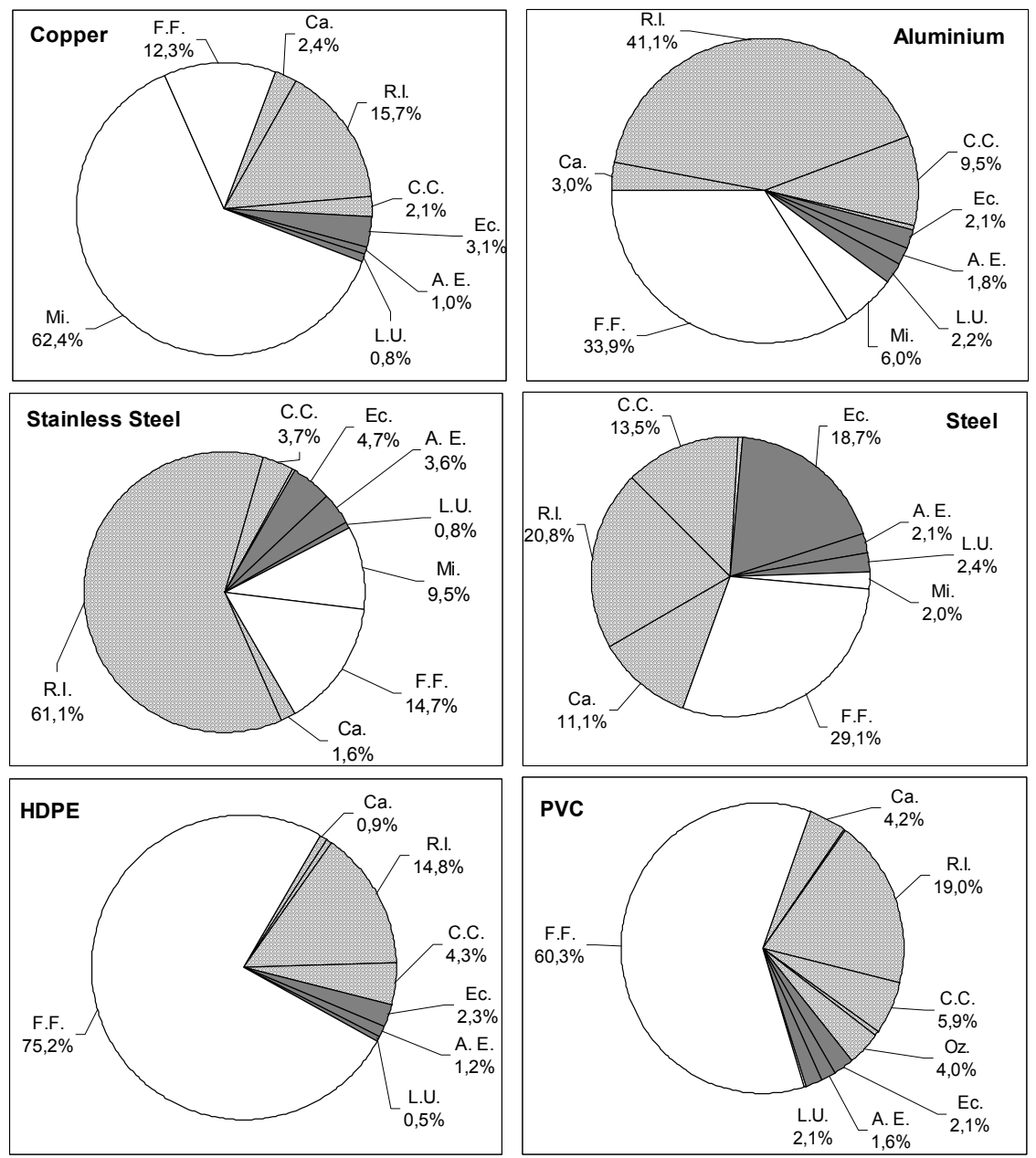

Figure 2: Percentage distribution into impact categories (abbreviations in Table 2).

Stainless steel is the material with the highest impact on Human Health; it is interesting to notice (Table 4) how emissions from stainless steel production are 
lower than those coming from aluminium production, apart from carbon monoxide and sulphur oxides.

Table 4: $\quad$ Main emissions to air associated with the Functional Unit.

\begin{tabular}{|c|c|c|c|c|c|}
\hline & $\mathrm{NO}_{\mathrm{x}}(\mathrm{g})$ & $\mathrm{CO}_{2}(\mathrm{~kg})$ & $\mathrm{CO}(\mathrm{g})$ & $\mathrm{SO}_{\mathrm{x}}(\mathrm{g})$ & $\mathrm{CH}_{4}(\mathrm{~g})$ \\
\hline Stainless steel & 10,1 & 5,3 & 28,5 & 342 & 15,7 \\
\hline Aluminium & 19,8 & 10 & 3,8 & 58 & 22,4 \\
\hline Copper & 8 & 5,2 & 2 & 136 & 10,2 \\
\hline
\end{tabular}

The environmental impact of stainless steel is far higher than steel $(0.89 \mathrm{Pt} / \mathrm{kg}$ and $0.08 \mathrm{Pt} / \mathrm{kg}$, respectively), due to the use of additional chemicals, mainly Nickel and Chrome, for its production.

As far as plastic materials are concerned, High Density Polyethylene (HDPE) and Polyvinylchloride (PVC) show close scores $(0.32 \mathrm{Pt} / \mathrm{kg}$ and $0.28 \mathrm{Pt} / \mathrm{kg}$, respectively); even the percentage distribution presented in Figure 2 is similar. Unlike ferrous and non-ferrous materials, the impact of PVC and HDPE on the category "Minerals" is negligible, as these materials are not extracted from earth but produced from chemicals through industrial processes.

Polyurethane (PUR) is by far the most impactive insulating material $(0.4$ $\mathrm{Pt} / \mathrm{kg})$; rock wool $(0.06 \mathrm{Pt} / \mathrm{kg})$ is more environmentally friendly than glass wool $(0.12 \mathrm{Pt} / \mathrm{kg})$. As well as with plastics, the impact due to the use of minerals is negligible for insulating materials.

The least affected damage category is "Ecosystem quality", whose contribution is higher than $20 \%$ only for steel.

If Individualist perspective is now considered, the most outstanding result is that the scores for copper, aluminium and stainless steel are far higher than those provided by Hierarchist perspective. Copper now shows an impact which is two orders of magnitude higher than all the other materials $(49.4 \mathrm{Pt} / \mathrm{kg})$, with the exception of aluminium and stainless steel, whose impact is "only" ten times lower (3.1 Pt/kg and 5.6 Pt/kg, respectively). On the contrary, the score of plastic and insulating materials is lower. In order to understand this considerable difference, some details must be given about Individualist perspective. The main point is that Individualists do not consider depletion of fossil fuels a real problem, as the long time perspective is not relevant for them; they do not care about consequences which will affect future generations. The consequences of this assumption are manifold:

- There is no impact in the category "Fossil Fuels"; this is the reason why all of the materials with an important contribution coming from this impact category (Plastics, Insulating) show a drop in their score.

- The normalisation factor for the damage category "Resources", which is the overall impact within Europe, also decreases when evaluated through Individualist perspective. This leads to the increase of the contribution within the remaining impact category, namely "Materials". 
Due to such relevant issues, Hierarchist perspective appears to be more balanced than Individualist perspective. Even the authors of the Eco-indicator 99 method suggest that Hierarchist perspective should be used as the default one, whereas Individualist may be useful for robustness and sensitivity analysis.

\section{The EPS 2000 method}

In the EPS 2000 method, twelve impact categories are defined, belonging to four damage categories, as shown in Table 5. Compared to the Eco-indicator 99 method, there is one more damage category, namely "Biodiversity", while the other categories are similar. Normalisation is not performed, while weighting is carried out by assessing the Willingness-to-pay (WTP), which is the amount of money people would pay to avoid environmental damages, from health diseases to disappearing of species. The monetary unit is named ELU. The final score is thus obtained by multiplying every impact indicator by the corresponding WTP, and is measured in ELU [10], [11].

Table 5: $\quad$ Categories and indicators defined in the Eco-indicator 99 method.

\begin{tabular}{|c|c|c|}
\hline $\begin{array}{l}\text { Damage } \\
\text { Category }\end{array}$ & Impact Category & Impact Indicator Unit \\
\hline \multirow{5}{*}{ Human Health } & Life Expectancy & Person-years \\
\hline & Severe morbidity & Person-years \\
\hline & Morbidity & Person-years \\
\hline & Severe Nuisance & Person-years \\
\hline & Nuisance & Person-years \\
\hline \multirow{5}{*}{$\begin{array}{c}\text { Ecosystem } \\
\text { Production } \\
\text { Capacity }\end{array}$} & Crop Growth Capacity & $\mathrm{kg}$ \\
\hline & Wood Growth Capacity & $\mathrm{kg}$ \\
\hline & Fish and Meat Production & $\mathrm{kg}$ \\
\hline & Soil Acidification & $\mathrm{H}^{+}$eq \\
\hline & Production Capacity for Water & $\mathrm{kg}$ \\
\hline $\begin{array}{c}\text { Abiotic Stock } \\
\text { Resources }\end{array}$ & Depletion of reserves & $\mathrm{ELU} / \mathrm{kg}$ \\
\hline Biodiversity & Species extinction & --- \\
\hline
\end{tabular}

As shown in Figure 3, only "Human Health" and "Abiotic Stock Resources" provide important contributions to the overall environmental impact. Copper is once again the most impactive material $(210 \mathrm{ELU} / \mathrm{kg})$, and its impact is mainly due to the depletion of abiotic resources $(99.4 \%)$, that is to say minerals and fossil fuels (Figure 4). Aluminium production turns out to be the most dangerous for human health, but stainless steel production is on the whole more impactive than aluminium, due to the high contribution of the category Resources. It should be noted that, according to EPS 2000 method, the weights attributed to extraction of copper, nickel and chrome is far higher than those associated with other metals, which explains the high score of stainless steel and copper. 
274 Eco-Architecture: Harmonisation between Architecture and Nature

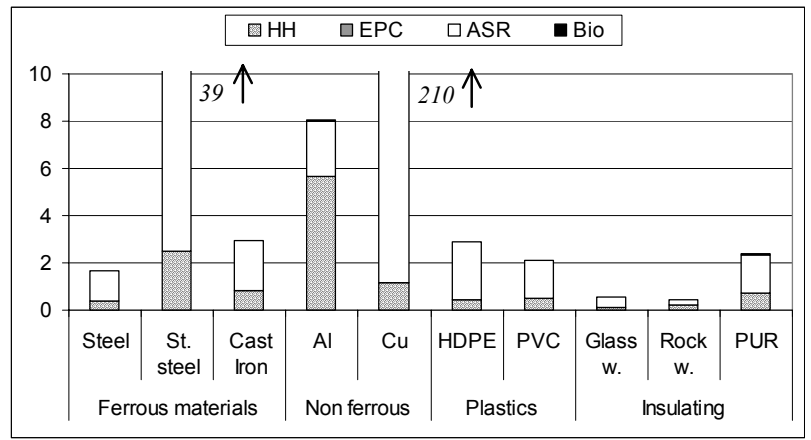

Figure 3: Environmental impact according to EPS 2000 method (ELU/kg).
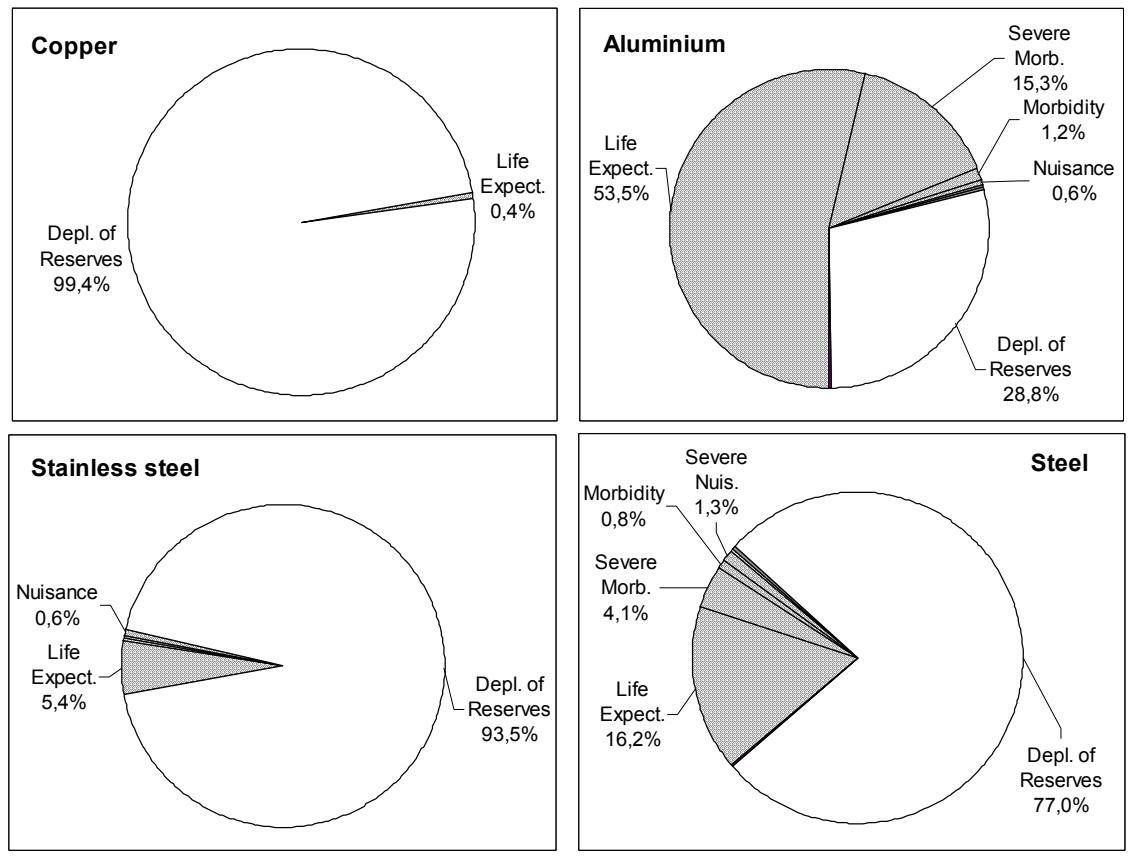

Figure 4: $\quad$ Percentage distribution into impact categories.

The difference between copper and all the other materials, with the exception of aluminium, is even more evident than when using Eco-indicator 99 with Individualist perspective. As far as plastic materials are concerned, HDPE is more impactive than PVC (2.9 ELU/kg and $2.1 \mathrm{ELU} / \mathrm{kg}$, respectively). Polyurethane (PUR) is once again the most impactive insulating material $(2.4 \mathrm{ELU} / \mathrm{kg})$, followed by glass wool $(0.6 \mathrm{ELU} / \mathrm{kg})$ and rock wool $(0.4 \mathrm{ELU} / \mathrm{kg})$. 


\section{Conclusions}

As shown in the previous sections, the potential environmental impact associated with the production and the use of a product or process may be evaluated according to different methodologies. Most of them follow the Life Cycle Assessment approach, but differ from each other because they adopt different impact categories and characterization is based on different models. On the other hand, a narrower perspective is adopted when using Embodied Energy, as it only takes into account the consumption of primary energy, while the effects of emissions on human health and ecosystem quality are not considered.

Table 6 shows how the environmental assessment may be influenced by the choice of the methodology; the materials considered in this paper are sorted according to their environmental impact, from the highest to the lowest one.

Table 6: Environmental ranking according to different methodologies.

\begin{tabular}{|c|c|}
\hline Materials & $\begin{array}{c}\text { Eco 99 } \\
\text { (Pt/kg) }\end{array}$ \\
\hline Copper & 1,40 \\
\hline St. steel & 0,89 \\
\hline Aluminium & 0,76 \\
\hline PUR & 0,40 \\
\hline HDPE & 0,32 \\
\hline PVC & 0,28 \\
\hline Cast Iron & 0,22 \\
\hline Glass wool & 0,12 \\
\hline Steel & 0,08 \\
\hline Rock wool & 0,06 \\
\hline
\end{tabular}

\begin{tabular}{|c|c|}
\hline Materials & $\begin{array}{c}\text { EPS 2000 } \\
\text { (ELU/kg) }\end{array}$ \\
\hline Copper & 210,2 \\
\hline St. steel & 38,9 \\
\hline Aluminium & 8,0 \\
\hline Cast Iron & 2,9 \\
\hline HDPE & 2,9 \\
\hline PUR & 2,4 \\
\hline PVC & 2,1 \\
\hline Steel & 1,7 \\
\hline Glass wool & 0,6 \\
\hline Rock wool & 0,4 \\
\hline
\end{tabular}

\begin{tabular}{|c|c|}
\hline Materials & $\begin{array}{c}\mathbf{E E} \\
\text { (MJ/kg) }\end{array}$ \\
\hline Aluminium & 164 \\
\hline PUR & 99,8 \\
\hline St. steel & 79,9 \\
\hline HDPE & 77,2 \\
\hline Copper & 72,9 \\
\hline PVC & 64,9 \\
\hline Cast Iron & 60 \\
\hline Glass wool & 31,3 \\
\hline Steel & 26,7 \\
\hline Rock wool & 15,7 \\
\hline
\end{tabular}

When using the methodologies following Life Cycle Assessment, slight differences can be found. The overall impression is the same, and only cast iron shows an important variation in its ranking, becoming the fourth most impactive material according to EPS 2000 method. Furthermore, inside every category of materials (Ferrous metals, Non-ferrous metals, Plastics, Insulating) the ranking is not altered, suggesting Stainless Steel, Copper, HDPE and PUR as the most impactive materials, respectively. However, even if the ranking is only slightly modified, the distance between the scores undergoes relevant changes: in EPS 2000, the Functional Unit for Copper and Stainless Steel present a score which is orders of magnitude higher than that of all the other materials. This will yield outstanding effects if products made up of several kilograms of different materials are to be compared.

Different results are provided by Embodied Energy, as Aluminium and PUR turns out to be the materials with the highest primary energy consumption; according to this approach, Copper is not the most impactive material. PUR and HDPE still represent the worst options for insulating materials and plastics, respectively. 
According to the results of the present study, the use of different methodologies to evaluate the potential environmental impact of products may influence the final results of the analysis. However, a clear environmental ranking of the materials used in technical equipments in buildings emerges.

\section{References}

[1] Guidelines for Life Cycle Assessment: a Code of Practice. Society for Environmental Toxicology, SETAC, Brussels, 1993.

[2] ETH-ESU: “Ökoinventare von Energiesystemen", Zürich 1996

[3] Loos B., De produktie van glas, glasvezel en glaswol, 1992.

[4] ISO 14040. Environmental management - life cycle assessment principles and framework. Geneva, Switzerland: International Standard Organization (ISO), 1997.

[5] ISO 14041. Environmental management - life cycle assessment - goal and scope definition and inventory analysis. Geneva, Switzerland: International Standard Organization (ISO), 1997.

[6] ISO 14042. Environmental management - life cycle assessment - life cycle impact assessment. Geneva, Switzerland: International Standard Organization (ISO), 1997.

[7] ISO 14043. Environmental management - life cycle assessment - life cycle interpretation. Geneva, Switzerland: International Standard Organization (ISO), 1997.

[8] Pennington, D.W., Potting., J. et al., Life Cycle Assessment Part 2: Current impact assessment practice, Environment International 30, pp.721-739, 2004.

[9] Goedkoop M., Spriensma R. The Eco-indicator 99. A damage oriented method for life cycle assessment. Methodology report. Amersfoort, Netherlands, Prè Consultants, 2001.

[10] Steen B., A systematic approach to environmental priority strategy in product development (EPS). Version 2000 - General system characteristic. Chalmers University of Technology, 1999.

[11] Steen B., A systematic approach to environmental priority strategy in product development (EPS). Version 2000 - Models and data of the default method. Chalmers University of Technology, 1999. 